\title{
Automation of management processes
}

\author{
Luis Ochoa Siguencia ${ }^{*}$ Piotr Halemba ${ }^{1}$ \\ ${ }^{1}$ The Jerzy Kukuczka Physical Education Academy in Katowice, Faculty of Sport and Tourism \\ Management, 40-065 Katowice, Poland ${ }^{l}$
}

\begin{abstract}
Artificial intelligence and service automation are the key to these kinds of new, product-related services. They increasingly penetrate the traditional mechanical and plant engineering sector and open up potentials for innovative services. Tourism services providers are going through rapid changes and the role of Information and Communication Technology, artificial intelligence and service automation is increasing in all spheres of the service management system. When the organization is threatened by environmental changes such as crises or competition as a result of information technology development or increased customer demands, the need for communication increases. This paper presents the first step of an ongoing investigation that focuses on the tourist services experiences and construction of management knowledge on undergraduate tourism management students. We report and discuss the result of a survey conducted involving the students of Tourism management at The Jerzy Kukuczka Physical Education Academy in Katowice - Poland. Structured questionnaires based on a 12-item importance scale were administered to a convenience sample of respondents. The authors present a new paradigm that emerges as a response to polarisation and treats communication as more receiver-centered, stakeholder $\square$ based, relationship $\square$ building $\square$ oriented and of strategic importance.
\end{abstract}

\section{Introduction}

Nowadays, the Internet has become the main source of information for young tourism customers looking for tourism services providers that will cover their expectations and needs [1]. The Internet network offers a great opportunity to communicate between business (B2B) like tourism offices and tourism services providers and consumer to Business (C2B) as in our study: Students of Tourism management undergraduate studies looking for tourism services and communicating with tourism services providers[2].

These activities: searching and communication are performed using different Internet applications, software, freeware, and web 2.0 that offers the possibility to use chats, communicators as well as discussion groups, internet forums, video conferencing, data file transfer programs and social networking sites [3].

\footnotetext{
*Corresponding author: 1.ochoa@,awf.katowice.pl
} 
The Internet is a unique medium that is used extensively in interpersonal and business communication. Nowadays, the use of mobile devices with an Internet connection is a common phenomenon. This fact, allows customers to easily get acquainted with the information that interests them in a precise time and situation [4]. Browsing websites, sending an e-mail, chatting, browsing social media, continuous 'contact with the world' anytime and anywhere - this is what the network gives us [5].

The Internet evolution can be clearly identified on the applications and way the content is presented on the web [7]. Mechanical engineering specialist work on internet robots that are able to use basic principles of tourism and critical skills needed to effectively create a travel itinerary. While travellers themselves will have an idea what they want, it is still down to the internet robots to identify and suggest the best flights, hotel rooms and ground transport arrangements ([3], [8]).

\section{Methodology}

Our research mainly focuses on the new approaches to information - communication management for transformation and change in tourism services providers. The advantages of searching for information and communication through the Internet and the changes on the way young customers search for tourism information providers are presented.

The research group was randomly from different Higher schools in the Silesian Region in Poland.. 121 women and 81 men. The average age was 22.5 (standard deviation of 1.53). More than half of the respondents lived in large cities of over one hundred thousand (54.7\%), 30.5 percent in smaller cities and 14.3 percent in rural areas.

The research was conducted at the turn of April 2015 and 2019 using an online questionnaire prepared on Google forms and sent to students using Facebook closed groups [4]. Statistica 13.1 package from Dell Inc. was used for statistical analysis.

The results available through the Google sheets have been transferred to Statistica13 of StatSoft, Inc. Single-choice closed questions, multiple choice and hierarchical questions were used in the questionnaire. For data analysis, descriptive statistics and quantitative techniques were used. To verify the hypothesis that two qualitative features in a population are independent, the $\chi^{2}$ test was used to compare the observed frequencies with the expected frequencies

$\chi^{2}-\sum_{i-1}^{n} \frac{\left(O_{i}-E_{i}\right)^{2}}{L_{i}}$

where:

$\mathrm{Oi}=$ the number of observations of type $\mathrm{i}$

$\mathrm{Ei}=$ the expected number of observations of type $\mathrm{i}$

\section{Research results}

The research group was randomly from different Higher schools in the Silesian Region in Poland. 202 students of Sport and Tourism Management participated in the online study, including 121 women and 81 men. The average age was 22.5 (standard deviation of 1.53). More than half of the respondents lived in large cities of over one hundred thousand $(54.7 \%), 30.5$ percent in smaller cities and 14.3 percent in rural areas.

Almost no one of the surveyed people can imagine life without the Internet and been disconnected to the Information and communication technology applications. Only one person has stated that he does not use the internet. In turn, four people recognize that they use the internet no more than an hour a day. Less than ten percent use it for 2 hours. The 
largest number of respondents determined that they spend between 2 and 4 hours in a day and one third between 4 and 6 hours. However, $13 \%$ spend on the internet for over 6 hours. It shows how much the global network is affecting our lifestyle nowadays.

Even more, astonishment can be raised by answering a question about the use of smartphones for this purpose. In the question: "How much of a percentage do you use it with a mobile phone", eight percent of respondents estimated that up to $25 \%$ In the set of 26 to $50 \%$ there were 16 percent of respondents, almost one fifth contracted in the range 50 $75 \%$ and most respondents $(57 \%)$ is defined as people who use Internet to a large extent (over 75\%) using a mobile phone. It shows how our reality is changing dynamically and shows the multi-functionality of smartphones, which long ago ended up being a simple device for voice communication.

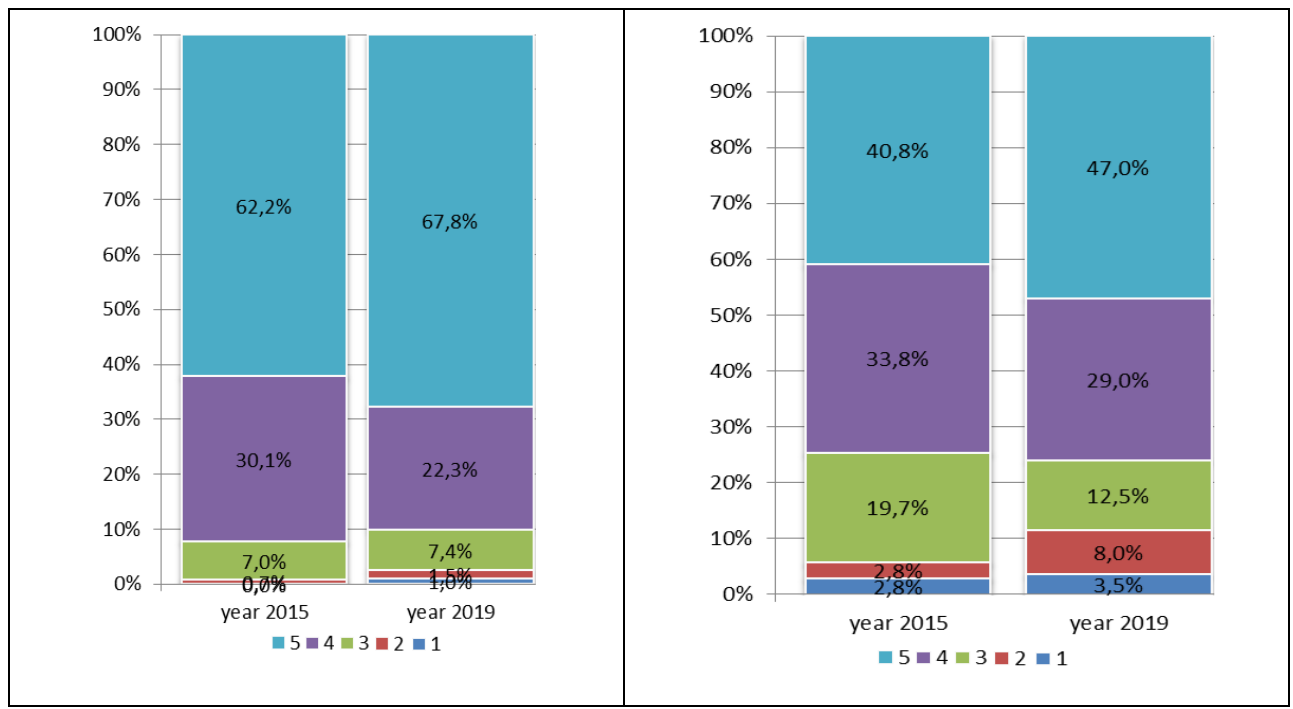

Fig. 1. Tourist services and Internet

Fig. 2. Search for attractions on Internet

Every year, young consumers are more and more convinced of the usefulness of the Internet as an assistant in finding interesting tourist services. On a scale from 1 to 5 where "1 - not at all useful and 5 - is very useful" this year $67.8 \%$ of respondents marked option 5 - and is $5.6 \%$ more than 4 years earlier. This results in increased use of the internet to search for interesting attractions. In the question about the use of the internet to the above, where "1 - I do not use at all and 5 - I use only the Internet", the group that only uses the internet grows. Almost half of the students use only the Internet for this purpose, which is an increase of $6.2 \%$ compared to the 2015 survey.

It may be interesting to ask what communication channels with the company are more and less popular. Question: "On a scale of 1 to 5, where 1 - is not needed at all, and 5 - is badly needed, evaluate the importance of individual communication channels between the client and the tourism company?" Was asked in relation to different communication options with the company. 


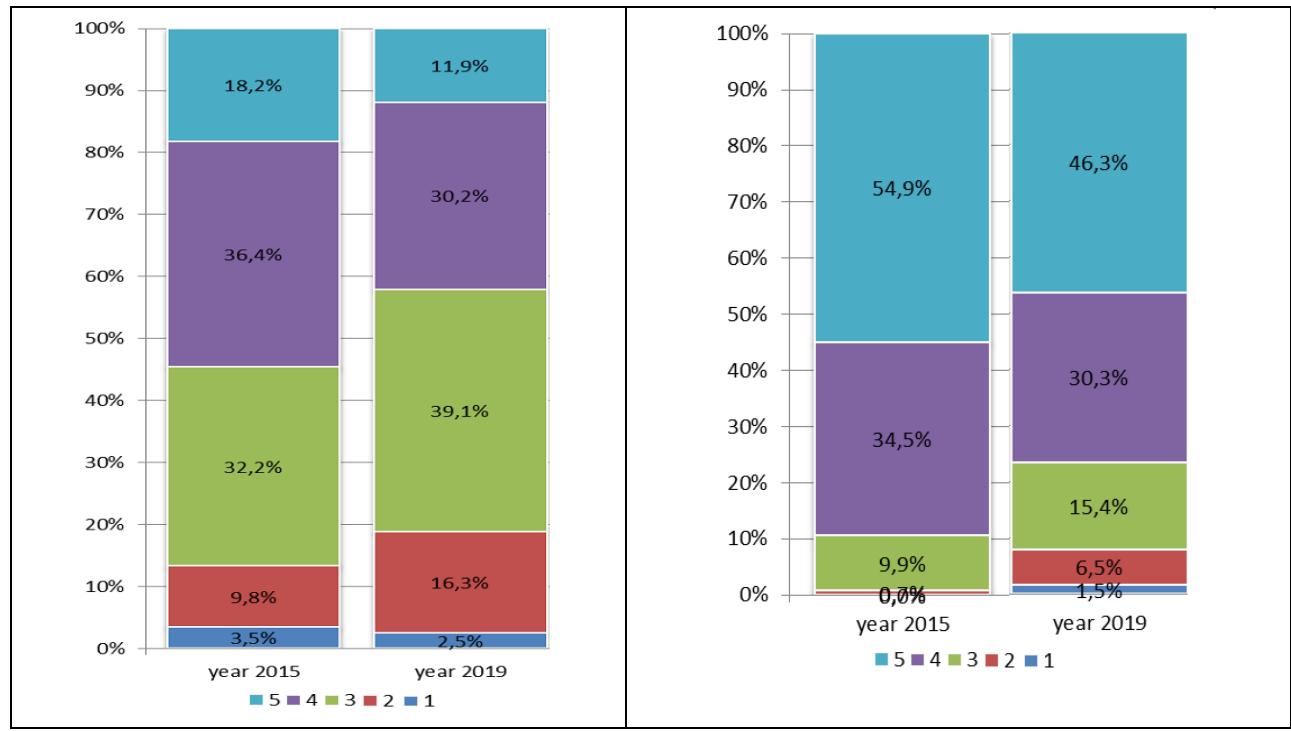

Fig. 3. Discussion groups

Fig. 4. E-mail

There is less attachment to such channels as the discussion group. A few years earlier, more than half of the respondents $(54.6 \%)$ assessed this form as important or very important. In this year's studies, only $42.1 \%$ have considered it so. Also, a form of communication such as e-mail is less important for the respondents. 4 years ago, $89.4 \%$ of respondents described this channel as important or very important, and this year already by almost $13 \%$ of respondents less so thinks.

So what in the opinion of students is gaining weight in communication? It turns out that a fan page on social networks is a beneficiary of the attention of young consumers. In 2015 $43.8 \%$ considered this channel to be very important, in $2019,55.4 \%$ think so. The channel, which is the chat, has been practically reviewed. Both this year, $44 \%(44.0 \%$ in 2019 , $44.8 \%$ in 2015) rated it as important or very important. Examining the differences between men and women, it can be noticed that in general women rank the importance of particular channels as communication possibilities. In the case of discussion groups, even statistically significant differences (chi2 $=15.22$ at $\mathrm{p}=0.00425)$ can be noticed for the other channels, the differences are noticeably smaller.

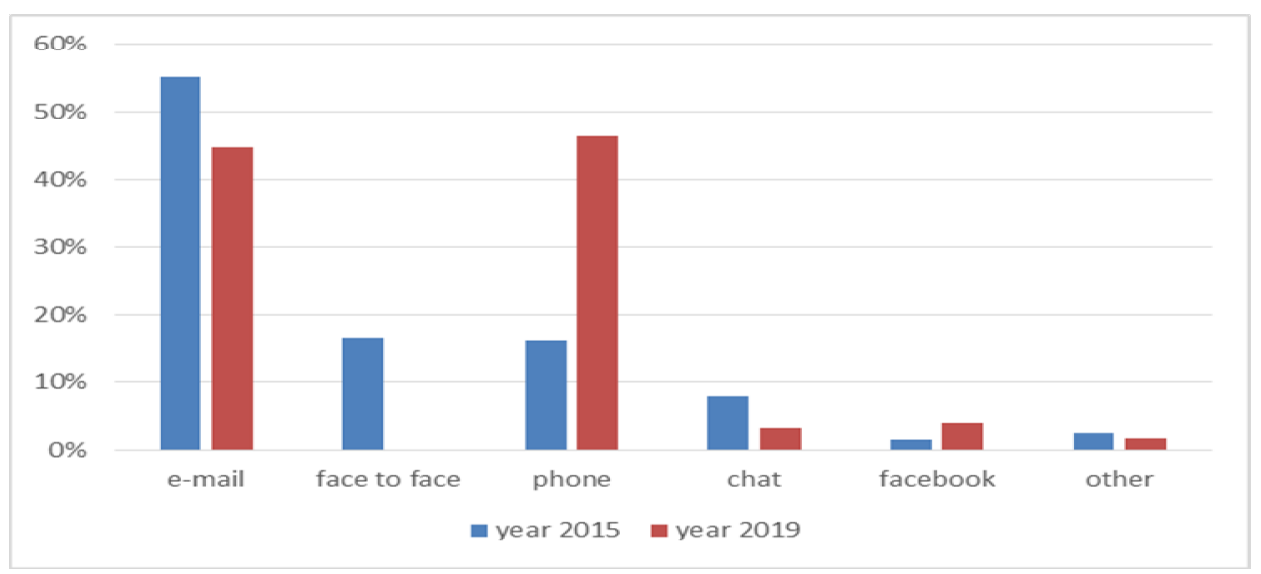

Fig. 5. Favourite way of communication with the company 
It is interesting to answer the question of what is your favorite way of communication with a travel company. In 2015 , most frequently e-mail was chosen - $55 \%$ of respondents chose this option. Next in the ranking was a personal face-to-face conversation (17\%) and a telephone conversation (16\%). In this year's studies, students completely ignored the conversation face-to-face. None of the respondents described it as a favorite, in the sense it lost the email, which was chosen by $45 \%$ of students but gained a phone call $(46 \%)$. There are also noticeable differences between men and women in channel preferences. $40.2 \%$ of women prefer e-mail, $30.8 \%$ of men, and almost half of men (46.2\%) and only $35.9 \%$ women prefer a telephone conversation when communicating with the company.

E-mail as a basic communication channel also underwent some evolution. Exactly, consumers have much higher requirements regarding the company's response time to a given question. Over half of respondents $(55.7 \%)$ believe that this time should not be longer than 12 hours. $39.7 \%$, in turn, gives the company time to answer from 12 to 24 hours, the remaining 4.9 percent of respondents from 24 to 48 hours. In similar studies conducted in 2013 , these requirements were much lower. In addition, you can see that women are more impatient than men. Over $60 \%$ of female students and $48 \%$ of students indicated that they would like to have an answer within 12 hours. These differences, however, are not statistically significant.

Having in mind the e-mail, it is worth looking at how often respondents receive tourist advertising and what they do with it. Every tenth $(9.85 \%)$ respondent specifies that he never gets one. Over one third (36.9\%) admit that every few weeks, and the largest group, $41.37 \%$, that every few days. This is not a bigger problem for students. The most popular behavior, in this case, is among young people simply ejecting the e-mail to the trash or spam. Two-thirds of respondents do so. However, a quarter of respondents read such letters for "satisfying curiosity". Almost 3 percent of respondents admit that they search the advertised tourist service on the Internet. The remaining 6\% are different behaviors such as "sometimes I read, sometimes not", "I mark but do not read".

\section{Summary}

Mechanical engineering specialist have a special place in the implementation and application of internet robots on the tourism industry. This robots are still under development but actually they are able to use basic principles of tourism and critical actions needed to effectively create a travel itinerary. While young travellers themselves will have an idea what they want, it is still down to the internet robots to identify and suggest the best flights, hotel rooms and ground transport arrangements.

The paper presents the methods of search for information and communication between youth customers and tourism providers businesses. The changes on the tools and devices youth customers use for searching and finding information on tourism are of great importance for tourism companies and mechanical engineering specialist. Along with the technological progress of the last five years, when the Internet has become one of the most important media and channels of communication, it is important to emphasis on the role of mobile applications, internet robots and smartphones with minimum 3 GB ram and 64 GB hard disk. Firms like Samsung, Apple, LG, HTC, Huawei, Honor, Xiaomi, OnePlus, Sony, Motorola, Nokia are providing better devices, capable of connecting to $5 \mathrm{G}$ networks that work better with internet robots. This fact must be taken into account when employing high qualify people on the tourism sector. 


\section{References}

1. S. Birudavolu \& B. Nag. Business Innovation and ICT Strategies. 10.1007/978-981-131675-3 (2019)

2. M. Lin Tsai, \& Y. Yi Chen. International Journal of Ad Hoc and Ubiquitous Computing. 2928 (2018).

3. A. Kopiec, L. Ochoa Siguencia, Z. Grodek Szostak. The potential of academic entrepreneurship: a chance for the development of the sme sector. Society. Integration. Education. Proceedings of the International Scientific Conference, 6, (2019)

4. E. Soegoto \& M. Rushamidiwinata. The Role of Internet in Business Strategy Using Trading Method. IOP Conference Series: Materials Science and Engineering, 407, (2018).

5. Z. Gródek-Szostak, D. Kajrunajtys, L. Ochoa Siguencia. Information Technology as a catalyst of innovative changes in enterprises. Society. Integration. Education. Proceedings of the International Scientific Conference, 6, (2019)

6. I. Liuberte. On Social Knowledge and Its Empirical Investigation in Contemporary Organisations, 81, (2019).

7. K. Sehl. An Introduction to Facebook's Secret Groups. Hootsuite Social Media Management (2018).

8. D. Christensen, From Needs Assessment to Needs Analysis, Performance Improvement, 57, (2018). 